\title{
Design and Evaluation of a Mobile-Based Application for Patients With Type 2 Diabetes: Case Study of Shariati Hospital in Tehran, Iran
}

\author{
Reza Safdari', Leila Shahmoradi ${ }^{1}$, Ali Garavand ${ }^{2}$, Nasim Aslani ${ }^{3}$, Aliasghar Valipour ${ }^{4}$, Hassan Bostan ${ }^{5 *}$ \\ ${ }^{1}$ Department of Health Information Management, Faculty Member of Paramedical School, Tehran University of \\ Medical Sciences, Tehran, Iran \\ ${ }^{2}$ Department of Health Information Management and Technology, Shahid Beheshti University of Medical Sciences, \\ Tehran, Iran \\ ${ }^{3}$ Department of Health Information Management, Iran University of Medical Sciences, Tehran, Iran \\ ${ }^{4}$ Department of Epidemiology, Faculty Member of Abadan School of Medical Sciences, Abadan, Iran \\ ${ }^{5}$ Department of Health Information Technology, Abadan School of Medical Sciences, Abadan, Iran
}

*Corresponding Author: Hassan Bostan, Lecturer, MSc in Health Information Technology, Department of Health Information Technology, Abadan School of Medical Sciences, Abadan, Iran. Tel: +98-9902488564,

Email: h.bostan68@gmail.com

Received May 1, 2018; Accepted July 4, 2018; Online Published September 1, 2018

\begin{abstract}
Background: With regard to the particularly high prevalence, cost, and number of disabilities associated with diabetes, increasing patients' knowledge and skills for managing the disease can help minimize the risks of complications.

Objective: The present study aimed to design and evaluate a mobile-based application with which patients with type 2 diabetes can increase their knowledge of and skills for managing their disease.

Methods: The current developmental-applied study was conducted in 2016 in a library and used a 2-step sectional format. The research population comprised 15 physicians and endocrinologists working in medical centers associated with Tehran University of Medical Sciences and 20 physicians and patients. Based on the library study, a checklist was designed and then distributed among participants. Their responses were analyzed using SPSS software version 20.

Results: The data was divided into 4 main sections: identity information (patient demographics), clinical information, education curriculum related to diabetes management, and program requirements for diabetes management, which consisted of 52 subsets. The evaluation of the system by doctors and patients showed that the system has high capabilities.

Conclusion: Mobile-based programs can help diabetics control blood glucose levels, reduce diabetes complications, and promote overall health.

Keywords: Diabetes, Self Care, Mobile Health
\end{abstract}

\section{Background}

The World Health Organization (WHO) has estimated that the number of people with diabetes will rise to 300 million by $2025 .^{1}$ Studies have shown that all complications of diabetes can be reduced through appropriate training, and the use of electronic health technology plays a positive role in providing healthcare to patients with chronic illness. ${ }^{2,3}$ The annual per-patient cost of traditional diabetes management has been estimated at $\$ 300$ to $\$ 1000$, while diabetes management through web-based systems is less than $\$ 50$ for each patient. ${ }^{4}$ Today, information and communication tools have created an area for providing health services that no longer requires a limited and specific location. These communication tools have also made it possible to provide primary care even in the home, which generates a new concept for home care. ${ }^{5}$ Some patients face obstacles such as distance or high traffic costs which limit their access to healthcare facilities and hospitals. With today's mobile technology, these patients can be trained and their health data will be available. ${ }^{\circ}$ Furthermore, limitations in resources and hospital beds preclude the complete in-hospital treatment and recovery of all patients. Mobile technology allows patients to monitor their illness. Health centers and healthcare organizations can also provide information technology and introduce new concepts to reduce costs and increase the quality and quantity of services. ${ }^{7}$ The ultimate goal in patient training on diabetes management is to improve the quality of care

Copyright $\odot 2018$ The Author(s). This is an open-access article distributed under the terms of the Creative Commons Attribution License (http:// creativecommons.org/licenses/by/4.0), which permits unrestricted use, distribution, and reproduction in any medium, provided the original work is properly cited. 
in order to reduce mortality, disability outcomes such as amputation, and costs. Moreover, scientifically training a patient or his family in disease management and the scientific supervision of the patient's disease management process by the patient himself are important in reducing the psychosocial complications of the disease for diabetics and their families. ${ }^{8}$ Managing diabetes consists of training (medication or insulin therapy), controlling patient blood glucose levels, using the principles of nutrition, and controlling patient activity levels. There are many innovative ways to facilitate disease management. Various studies have shown that the use of information technology in managing chronic diseases and patient-centered care approaches, such as controlling vital symptoms, medical counseling, and providing educational information by mobile applications can be very helpful. ${ }^{9}$ The WHO introduced the use of e-learning as a good communication channel between patients and healthcare providers. ${ }^{10}$ Many studies have been conducted in recent years on the use of various mobile applications by patients with various types of diabetes. As an example, Wu et al concluded that the use of mobile apps has had a positive effect on the efficacy of self-management interventions in the glycemic control of diabetes patients. ${ }^{11}$ Boyle et al also concluded in their study that, "The use of apps to record blood glucose was the most favored function in apps used by people with diabetes, with interest in insulin dose calculating function." 12

Clements and Staggs in their study referred to the importance of using a mobile app in a patient's routine care for controlling the blood sugar of young people with type 1 diabetes. $^{13}$

\section{Objective}

Early research showed that in Iran, for self-management of diabetes, patients were given written advice, sometimes in the form of multi-page pamphlets, most of which provided brief, incomplete, and repetitious information. Moreover, there was no way for specialists to supervise the implementation of any management strategies. Therefore, this study aimed to design and evaluate a mobile application for patients with type 2 diabetes in Tehran's Shariati hospital in 2016.

\section{Methods}

The present developmental study was conducted in 2016 in a library and used the sectional format in 3 steps. First, data was collected using a checklist based on Iranian Diabetes Association criteria and other library studies, ${ }^{14-17}$ The checklist was given to the study participants to complete the second step. It contained 52 open- and closed-ended questions in 5 parts. The first part focused on the individual profiles of the study participants (3 open-ended questions). The other 4 parts focused on the patient's identity ( 4 closedended questions), clinical information (11 closed-ended questions), disease management of diabetes (19 closedended questions), and the cases of the required program (15 closed-ended questions). Each of the 4 last questions had 2 options: "necessary" (one point) and "unnecessary" (zero points). Comments were obtained from 6 experts in the fields of health information management, medical informatics, and endocrinology from the Tehran University of Medical Sciences who reviewed the contents of the checklist. After reviewing their comments, the checklist was redesigned. The research community included Ph.D. specialists and endocrinologist of Shariati hospital. Sampling was done according to the purposive sampling method, and comments were received from 15 patients. The criteria for choosing doctors to participate in the study were their interest in research and their familiarity with health programs. The data obtained from the questionnaires completed by participating physicians was analyzed using SPSS version 20 and descriptive statistics. After the results from the 2 previous steps was analyzed, a software program was developed by 2 expert programmers based on the Java programming language in the Android operation system using Eclipse software. In most studies, the interface for Android software is written with Java, and Android supports all languages, including Persian. Therefore it was used for the application developed in this study. The developed software is illustrated in Figure 1. In the third step of the study, comments about the software from 20 specialists and patients with type 2 diabetes were obtained through a questionnaire comprising 30 questions in 4 main parts based on previous studies. The content validity (content validity index [CVI] for necessity and content validity ratio [CVR] for simplicity, relevance, and clarity) of the questionnaire was measured by the opinions of 10 experts in Health Information Management, Medical Informatics and Programming; results of $\mathrm{CVR}=80 \%$ and $\mathrm{CVI}=80 \%$ were obtained and included: $(a)$ general information about the program (including the general function of the program, program readiness, user's feelings about working with the program, general design of the program, continuous work with the program, and the ability to perform program settings); (b) the screen (including the degree of readability of the letters on the screen, the use of specific expressions to facilitate user's tasks, the organization of program information, and the

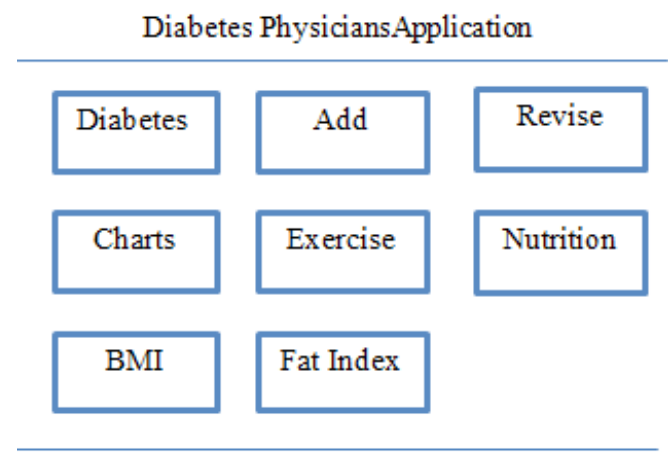

Developer: Hassan Bostan, MSc in HIT

Figure 1. A Generalized Schedule of Mobile-Based Design for Type 2 Diabetes 
sequence of the screens); (c) terms and information used in the program (including terms related to the user's takes, the placement of messages on the screen, the message to record the essential data, program messages to complete the user's tasks, error messages, learning to work with the program, finding new program features through trial and error, learning names and application commands, the ability to perform tasks quickly and easily, guidance messages on the screen, and supplementary education references); and ( $d$ ) the general capabilities of the program (including the loading speed of the application pages, the program validity, the multiplicity of program capabilities, the correction of user errors during data entry, and the design appropriateness for users of different levels). These features were evaluated using a 10-part range of scores (0 to 9 ) with 0 to $3=$ inappropriate, 3 to $6=$ relatively suitable, and 7 to $9=$ appropriate. The preprogram pattern was given to 20 physicians and patients (people who were capable of using smart phones), and they were asked to work with the program in a loud voice and express their opinions. After installing and entering the program, patients recorded data related to blood glucose level, insulin usage, and average activity level per day, and studied the educational materials of the program. It should be noted that loud thinking was essentially an assessment method used in psychology; today, however, it is commonly used by computer scientists for evaluating computer program interfaces. ${ }^{18}$ At all stages of data collection, the consent of the individuals was considered; if someone did not provide consent, s/he was not given a questionnaire. Participants were assured that the information collected would remain confidential until the end of the investigation.

\section{Results}

The data elements required in the program consisted of 4 main groups: patient demographics information, patient clinical information, management of diabetes by the patient, and the features required in the program.

Table 1 shows the importance of the data available in the clinical information of the patient. Such information as a familial history of diabetes, other illnesses such as heart disease, blood pressure, asthma, etc, and other medications being consumed unnecessarily, was compiled.

The third section contained data elements on diabetes management that focused on six main areas of keeping blood glucose at normal levels: insulin intake, nutrition, management of the complications of diabetes, mobility, patient activity, and other information.

As seen in Table 2, which relates to the management of diabetes by the patient, most doctors in the study identified all the mentioned data elements as necessary, except for the rest of the required information.

Table 3 shows the frequency distribution of user responses to the cases required in the program. The program information section relates to capabilities of which most physicians considered the data elements to be essential, although the data element "use of the warning" was not necessary.

The application in this study uses Eclipse software version 13, which provides programming conditions in the Android environment. Based on the results of the information requirement, the program was first designed in the form of an Eclipse programming environment using Java Edition software version 8 and based on the rapid development of the software for the Android operating system.

Users provided suggestions for completing and improving the program. Patients' suggestions were to include a chart of previous blood glucose and insulin values, menus for accessing other pages from the current page, and appropriate messages displayed when data was recorded successfully.

The user suggestions were reviewed, and those items that could be run were included in the design of the program and in the final version of the mobile-based program for type 2 diabetic patients, as shown in Figure 1.

After being designed and developed, the application was evaluated by physicians and patients. The results

Table 1. The Necessity of Information Elements in Patient Clinical Information in a Mobile Application for Type 2 Diabetes Patients

\begin{tabular}{|c|c|c|c|c|c|}
\hline \multirow{2}{*}{ Row } & \multirow{2}{*}{ Clinical information } & \multicolumn{2}{|c|}{ Necessary } & \multicolumn{2}{|c|}{ Unnecessary } \\
\hline & & No. & $\%$ & No. & $\%$ \\
\hline 1 & Diabetes and its variants & 15 & 100 & 0 & 0 \\
\hline 2 & Complications of diabetes & 12 & 80 & 3 & 20 \\
\hline 3 & Autopsy in diabetes & 11 & 73.3 & 4 & 23.7 \\
\hline 4 & Medications being consumed & 9 & 60 & 6 & 40 \\
\hline 5 & Familial history of diabetes & 3 & 20 & 12 & 80 \\
\hline 6 & Other diseases like heart disease, blood pressure, asthma, etc & 3 & 20 & 12 & 80 \\
\hline 7 & Other medications being consumed & 6 & 40 & 9 & 60 \\
\hline 8 & The latest amount of glycosylated hemoglobin (HbA1c) & 11 & 73.3 & 4 & 23.7 \\
\hline 9 & The number of insulin injections per day & 13 & 86.6 & 2 & 13.4 \\
\hline 10 & The number of daily blood glucose measurements & 15 & 100 & 0 & 0 \\
\hline 11 & The average of glucose (less than 70) in a week & 4 & 26.6 & 11 & 73.4 \\
\hline 12 & The number of convulsions due to decrease in blood glucose in the past month & 3 & 20 & 12 & 80 \\
\hline
\end{tabular}


Table 2. The Necessity of Data Elements Required in the Illness Management Division by the Patient in a Mobile Application for Patients with Type 2 Diabetes

\begin{tabular}{|c|c|c|c|c|c|c|}
\hline \multirow{2}{*}{ Row } & & \multirow{2}{*}{ Self-management of the Patient } & \multicolumn{2}{|c|}{ Necessary } & \multicolumn{2}{|c|}{ Unnecessary } \\
\hline & & & No. & $\%$ & No. & $\%$ \\
\hline 13 & \multirow{3}{*}{$\begin{array}{l}\text { Keep blood glucose at } \\
\text { normal levels }\end{array}$} & Recording blood glucose level (5 times a day) & 15 & 100 & 0 & 0 \\
\hline 14 & & Training on how to measure blood glucose & 11 & 73.3 & 4 & 23.7 \\
\hline 15 & & Training on how to use glucometers & 14 & 93.3 & 1 & 6.7 \\
\hline 16 & \multirow{5}{*}{ Taking insulin } & Recording the time of insulin injections & 14 & 93.3 & 1 & 6.7 \\
\hline 17 & & Recording the amount of injected insulin & 14 & 93.3 & 1 & 6.7 \\
\hline 18 & & Training on how to inject insulin & 12 & 80 & 3 & 20 \\
\hline 19 & & Providing information about the type of insulin used & 9 & 60 & 6 & 40 \\
\hline 20 & & Training on the necessary measures when taking insulin & 10 & 66.6 & 5 & 33.4 \\
\hline 25 & \multirow{2}{*}{$\begin{array}{l}\text { Nutrition of the } \\
\text { patient }\end{array}$} & Training on proper nutrition for the patient & 9 & 60 & 6 & 40 \\
\hline 26 & & Providing information on proper nutrition for the patient & 11 & 73.3 & 4 & 26.7 \\
\hline 27 & \multirow{4}{*}{$\begin{array}{l}\text { Managing } \\
\text { Complications of } \\
\text { Diabetes }\end{array}$} & Training on how to prevent increases and reductions in blood glucose levels & 8 & 53.3 & 7 & 46.7 \\
\hline 28 & & $\begin{array}{l}\text { Training on the necessary measures to take when one's blood glucose rises or } \\
\text { falls }\end{array}$ & 15 & 100 & 0 & 0 \\
\hline 29 & & Recommendations for preventing coma caused by diabetes & 12 & 80 & 3 & 20 \\
\hline 30 & & $\begin{array}{l}\text { Training on how to care for feet, eyes, kidneys, and other organs affected by } \\
\text { diabetes }\end{array}$ & 12 & 80 & 3 & 20 \\
\hline 31 & \multirow{2}{*}{$\begin{array}{l}\text { Mobility and activity } \\
\text { of the patient }\end{array}$} & Recording the amount of daily activity & 15 & 100 & 0 & 0 \\
\hline 32 & & Recording the type of daily activity & 11 & 73.3 & 4 & 26.7 \\
\hline 33 & \multirow{3}{*}{$\begin{array}{l}\text { Other required } \\
\text { information }\end{array}$} & Providing information about diabetes science associations & 5 & 33.3 & 10 & 66.7 \\
\hline 34 & & Providing information about research centers of endocrinology and metabolism & 6 & 40 & 9 & 60 \\
\hline 35 & & Providing information about specialized clinics for diabetes and endocrinology & 2 & 13.3 & 13 & 86.7 \\
\hline
\end{tabular}

Table 3. The Necessity of Data Elements for the Features Required in a Mobile Application for Patients with Type 2 Diabetes

\begin{tabular}{|c|c|c|c|c|c|}
\hline \multirow{2}{*}{ Row } & \multirow{2}{*}{ Answers System Capabilities } & \multicolumn{2}{|c|}{ Necessary } & \multicolumn{2}{|c|}{ Unnecessary } \\
\hline & & No. & $\%$ & No. & $\%$ \\
\hline 36 & Display the history of recording data & 14 & 93.3 & 1 & 6.7 \\
\hline 37 & Display the time of data measurement & 14 & 93.3 & 1 & 6.7 \\
\hline 38 & Display changes in blood glucose in chart form & 11 & 73.3 & 4 & 26.7 \\
\hline 39 & Display previously recorded data of the patient & 14 & 93.3 & 1 & 6.7 \\
\hline 40 & BMI calculator & 15 & 100 & 0 & 0 \\
\hline 41 & Calculate fat index & 9 & 60 & 6 & 40 \\
\hline 42 & Using alarms & 6 & 40 & 9 & 60 \\
\hline 43 & Display changes in blood glucose in chart form & 15 & 100 & 0 & 0 \\
\hline 44 & Display blood pressure changes in chart form & 13 & 87.1 & 2 & 12.9 \\
\hline 45 & Show weight in chart form & 15 & 100 & 0 & 0 \\
\hline 46 & Show activity in chart form & 9 & 60 & 6 & 40 \\
\hline 47 & Display medications in chart form & 8 & 53.3 & 7 & 46.7 \\
\hline 48 & Display carbohydrates in chart form & 12 & 80 & 3 & 20 \\
\hline 49 & Show pulse rates in chart form & 11 & 73.3 & 4 & 26.6 \\
\hline
\end{tabular}

are presented in Table 4 in 4 main dimensions: general information of the program, the screen, terminology and information used in the program, and the general capabilities of the program. These dimensions were evaluated in 30 questions with 10 scoring options. At this stage, the comments of 8 experts ( 4 male and 4 female) and 12 patients ( 7 male and 5 female) from Shariati hospital in Tehran were collected. All participants were able to use a smartphone.

Based on the evaluation results, the necessary corrections were made in the program. The page view was upgraded to improve the user interface and increase user satisfaction. Also based on the suggestion of the users, more training was given in the program on diabetic patients' medications. In recording data or completing each item, there was the possibility of entering inaccurate and non-valid data; therefore, validation fields were used to control the input data and prevent errors in data insertion. To provide guidance to users and inform them of the successful recording of data, messages were included in the forms.

Based on the suggestions of the users and because some patients may use different types of insulin injections at different times, and that it is sometimes necessary to have blood glucose changes checked occasionally and on consecutive days by a specialist, the program had to be capable of displaying insulin and blood glucose charts in each turn individually. Therefore, the capability of showing blood glucose and insulin charts from previous days, separated by 5 turns, and visible to the patients was added 
Table 4. Evaluation of the Mobile Application Assessment for Type 2 Diabetes

\begin{tabular}{|c|c|c|c|c|c|}
\hline \multirow{2}{*}{ Row } & \multirow{2}{*}{ The Main Spectra for Evaluation } & \multicolumn{2}{|c|}{ Physicians } & \multicolumn{2}{|c|}{ Patients } \\
\hline & & Average Scores of 9 & SD & Average Scores of 9 & SD \\
\hline 1 & General information of the program & 7.42 & 0.707 & 7.78 & 0.577 \\
\hline 2 & The screen & 6.97 & 0.801 & 7.01 & 0.621 \\
\hline 3 & Terms and information used in the program & 7.53 & 0.741 & 7.21 & 0.681 \\
\hline 4 & General capabilities of program & 6.53 & 0.830 & 6.50 & 0.706 \\
\hline 5 & Total & 7.11 & & 7.13 & \\
\hline
\end{tabular}

All questions were scored in a range of 0 to 9.

to the program.

Considering the importance of the patient's diet in controlling diabetes, the field of nutrition education was expanded and more content was developed for the educational section of the program.

\section{Discussion}

In the present study, all participants identified individual information as essential. In their study, Ku et al identified the existence of demographic elements in the app. ${ }^{16}$

The results of the study in the area of diabetes management showed that all physicians identified recording blood glucose (5 times a day), training on measures to increase or reduce blood glucose, recording of the patient's daily activity, training on how to use a glucometer, recording of the time of insulin injections, recording of the amount of insulin injected as essential. Prevention of increasing or decreasing blood glucose levels, providing information on endocrine and metabolic research institutes have found it unnecessary to provide information on specialized diabetes and endocrinology clinics (all these components were found to be unnecessary in the app by physicians). Holmen et al achieved similar results in their study. ${ }^{19}$

The findings showed that all physicians identified these items as essential: BMI calculators, graphs of blood glucose changes, graphs of weight, the ability to display the date of data recording, the ability to display the time of the data, displaying the patient's previously recorded data, displaying blood pressure changes in chart form, displaying patient's carbohydrate intake in chart form, displaying blood glucose changes in chart form, displaying pulse rates in chart form, displaying exercise levels in chart form, and calculating the fat index. Similar results have been obtained in many similar studies. ${ }^{17-21}$ Moreover, the display of medications in chart form and the use of the warning were deemed unnecessary.

Peres et al combined mobile-based applications for managing diabetes with an artificial neural network and concluded that an artificial neural network can be used in this system to predict some outcomes of a patient's illness or condition, such as reducing or increasing blood glucose levels. ${ }^{20}$ This result is consistent with that of the present study.

The software developed in this study has graphs of blood glucose changes. In another study, Holopainen proposed a model for the use of mobile-based applications for training on diabetes management. The model measured glucose levels by a sensor, which automatically or manually sent the information to the application installed on the mobile phone. In Holopainen's proposed model, the information sent by each user after processing by the central server was redistributed to the user for viewing through the mobile phone. $^{21}$

The results showed that the latest amount of glycosylated hemoglobin (HbA1c) is an important element in the application. In 2008, a software for managing diabetes designed by Quinn et al was provided to patients in an intervention group and patients were treated in the usual way. Comparing the rates of glycosylated hemoglobin in both groups showed a decrease of $2.3 \%$ in patients who used Doc's Diabetes Management program. ${ }^{22}$

Many studies conducted evaluations after the software had been ${ }^{2-24}$; therefore, many studies have focused on the necessity of the data elements regarding the features required in mobile programs for the self-management of diabetes.

The required stage of the study showed that most of the problems mentioned by type II diabetic patients were in the areas of self-care education activities. Many studies have highlighted the importance of using cellular facilities to educate the patient for self-care. ${ }^{11,25-27}$

The results of the software evaluation showed that all users were satisfied with the appearance and content features of the software and that it was comfortable to use. They also indicated that they would recommend the software to other type 2 diabetic patients. These findings indicated that type 2 diabetic patients had a high level of satisfaction with the software. Many recent studies in the field of health technology acceptance have implied the ease of using it and the importance of satisfying users. ${ }^{28,29}$

\section{Conclusion}

This level of acceptance among users of the developed software can be attributed to the presence of patients and doctors in the design process of the software, the feedback received from them, and the incorporation of their comments in improving the software.

Finally, the use of educational software by diabetics was effective in increasing their awareness of the proper care of the disease. This increase in awareness was also effective on the level of awareness of users based on self-awareness as well as user awareness on the basis of the test. The results 


\section{Research Highlights}

\section{What Is Already Known?}

The number of people with diabetes will rise to 300 million by 2025.1 Studies have shown that all complications of diabetes can be reduced through appropriate training, and the use of electronic health technology plays a positive role in providing healthcare to patients with chronic illness. This study aimed to design and evaluate a mobile application for patients with type 2 diabetes in Tehran's Shariati hospital in 2016.

\section{What This Study Adds?}

The use of educational software by diabetics was effective in increasing their awareness of the proper care of the disease. Through the use of this program, the awareness of the patient regarding managing their illness will be increased, and many unnecessary referrals to health centers and imposed costs will be prevented. It is also suggested that researchers take heed of the items and data elements extracted from the results of this study in developing other similar software.

of many studies have implied that more clinical studies on applications, especially in the field of diabetes management, are needed. ${ }^{19,30}$ Based on the results of this study and the proper user evaluations of the program provided by this study, it is recommended that this application be widely used for self-management of patients with type II diabetes. Through the use of this program, the awareness of the patient regarding managing their illness will be increased, and many unnecessary referrals to health centers and imposed costs will be prevented. It is also suggested that researchers take heed of the items and data elements extracted from the results of this study in developing other similar software. Moreover, the use of this program can lead to patients being referred to care services. Considering that few studies have been done in this field in Iran, it is suggested that more research be conducted regarding the design and evaluation of software to help patients manage themselves and increase the community health level. It is further suggested that other researchers use the results of this study to determine the effectiveness of this application and other similar applications on the trend of treatment and healthcare among patients. With regard to the positive results regarding the evaluation of the developed application, it is suggested that policymakers use this application in higher experimental studies.

\section{Authors' Contributions}

RS and LS designed the study and supported all steps of the study. HB gathered data and programmed the software. AG and NA wrote the paper, and AV revised and translated the paper.

\section{Conflict of Interest Disclosures}

The authors declare that they have no conflicts of interest.

\section{Ethical Approval}

Due to ethical considerations, the names of the patients and physicians were not mentioned. This study was approved by Shariati Hospital's Ethics Committee and the School of Allied Medical Sciences of Tehran University of Medical Sciences with code No. 280/3/f/52.

\section{References}

1. World Health Organization. Definition, diagnosis and classification of diabetes mellitus and its complications. Geneva, Switzerland: World Health Organization; 1999.

2. Ahmadi M, Aslani N. Capabilities and advantages of cloud computing in the implementation of electronic health record. Acta Inform Med. 2018;26(1):24-28. doi:10.5455/ aim.2018.26.24-28.

3. Mulcahy $K$, Maryniuk $M$, Peeples $M$, et al. Diabetes selfmanagement education core outcomes measures. Diabetes Educ. 2003;29(5):768-770, 773-784, 787-768 passim. doi:10.1177/014572170302900509.

4. Wantland DJ, Portillo CJ, Holzemer WL, Slaughter R, McGhee EM. The effectiveness of Web-based vs. non-Web-based interventions: a meta-analysis of behavioral change outcomes. J Med Internet Res. 2004;6(4):e40. doi:10.2196/jmir.6.4.e40.

5. Pinciroli $F$, Corso $M$, Fuggetta $A$, Masseroli $M$, Bonacina S, Marceglia S. Telemedicine and e-health. IEEE Pulse. 2011;2(3):62-70. doi:10.1109/mpul.2011.941524.

6. Piette JD. Interactive behavior change technology to support diabetes self-management: where do we stand? Diabetes Care. 2007;30(10):2425-2432. doi:10.2337/dc07-1046.

7. Norris SL, Lau J, Smith SJ, Schmid CH, Engelgau MM. Selfmanagement education for adults with type 2 diabetes: a meta-analysis of the effect on glycemic control. Diabetes Care. 2002;25(7):1159-1171. doi:10.2337/diacare.25.7.1159.

8. Funnell MM, Kruger DF, Spencer M. Self-management support for insulin therapy in type 2 diabetes. Diabetes Educ. 2004;30(2):274-280. doi:10.1177/014572170403000220.

9. Marrero DG, Vandagriff JL, Kronz $K$, et al. Using telecommunication technology to manage children with diabetes: the Computer-Linked Outpatient Clinic (CLOC) Study. Diabetes Educ. 1995;21(4):313-319. doi:10.1177/014572179502100409.

10. Ibbini M. A Pl-fuzzy logic controller for the regulation of blood glucose level in diabetic patients. J Med Eng Technol. 2006;30(2):83-92. doi:10.1080/03091900500049528.

11. WuY, Yao X, Vespasiani G, et al. Mobile App-Based Interventions to Support Diabetes Self-Management: A Systematic Review of Randomized Controlled Trials to Identify Functions Associated with Glycemic Efficacy. JMIR Mhealth Uhealth. 2017;5(3):e35. doi:10.2196/mhealth.6522.

12. Boyle L, Grainger R, Hall RM, Krebs JD. Use of and Beliefs About Mobile Phone Apps for Diabetes Self-Management: Surveys of People in a Hospital Diabetes Clinic and Diabetes Health Professionals in New Zealand. JMIR Mhealth Uhealth. 2017;5(6):e85. doi:10.2196/mhealth.7263.

13. Clements MA, Staggs VS. A Mobile App for Synchronizing Glucometer Data: Impact on Adherence and Glycemic Control Among Youths With Type 1 Diabetes in Routine Care. J Diabetes Sci Technol. 2017;11(3):461-467. doi:10.1177/1932296817691302.

14. Iranian Diabetes Society. Books Set. http://www.ids.org.ir/ Accessed 15 Feb 2015.

15. Farjami A, Haghpanah S, Arasteh P, et al. Epidemiology of hereditary coagulation bleeding disorders: A 15-year experience from southern Iran. Hosp Pract Res. 2017;2(4):113 117. doi:10.15171/HPR.2017.27.

16. Ko GT, So WY, Tong PC, et al. From design to implementation-- 
the Joint Asia Diabetes Evaluation (JADE) program: a descriptive report of an electronic web-based diabetes management program. BMC Med Inform Decis Mak. 2010;10:26. doi:10.1186/1472-6947-10-26.

17. Jennings A, Powell J, Armstrong N, Sturt J, Dale J. A virtual clinic for diabetes self-management: pilot study. J Med Internet Res. 2009;11(1):e10. doi:10.2196/jmir.1111.

18. Atkinson E. Web analytics and think aloud studies in web evaluation: understanding user experience. London University; 2007.

19. Holmen $\mathrm{H}$, Wahl AK, Cvancarova Smastuen M, Ribu L. Tailored Communication Within Mobile Apps for Diabetes Self-Management: A Systematic Review. J Med Internet Res. 2017;19(6):e227. doi:10.2196/jmir.7045.

20. Perez-Gandia C, Facchinetti A, Sparacino G, et al. Artificial neural network algorithm for online glucose prediction from continuous glucose monitoring. Diabetes Technol Ther. 2010;12(1):81-88. doi:10.1089/dia.2009.0076.

21. Holopainen A, Galbiati F, Voutilainen K, EHIT L. Use of modern mobile technologies to enhance remote self-care services. Helsinki, Finland: 2006;139.

22. Quinn CC, Clough SS, Minor JM, Lender D, Okafor MC, GruberBaldini A. WellDoc mobile diabetes management randomized controlled trial: change in clinical and behavioral outcomes and patient and physician satisfaction. Diabetes Technol Ther. 2008;10(3):160-168. doi:10.1089/dia.2008.0283.

23. Roek MG, Welschen LM, Kostense PJ, Dekker JM, Snoek FJ, Nijpels G. Web-based guided insulin self-titration in patients with type 2 diabetes: the Di@log study. Design of a cluster randomised controlled trial [TC1316]. BMC Fam Pract. 2009;10:40. doi:10.1186/1471-2296-10-40.

24. Cho JH, Lee HC, Lim DJ, Kwon HS, Yoon KH. Mobile communication using a mobile phone with a glucometer for glucose control in Type 2 patients with diabetes: as effective as an Internet-based glucose monitoring system. J Telemed Telecare. 2009;15(2):77-82. doi:10.1258/jtt.2008.080412.

25. Dobson R, Whittaker R, Murphy R, et al. The use of mobile health to deliver self-management support to young people with type 1 diabetes: a cross-sectional survey. JMIR Diabetes. 2017;2(1):e4. doi:10.2196/diabetes.7221.

26. Goyal S, Nunn CA, Rotondi M, et al. A Mobile App for the Self-Management of Type 1 Diabetes Among Adolescents: A Randomized Controlled Trial. JMIR Mhealth Uhealth. 2017;5(6):e82. doi:10.2196/mhealth.7336.

27. Gao C, Zhou L, Liu Z, Wang H, Bowers B. Mobile application for diabetes self-management in China: Do they fit for older adults? Int J Med Inform. 2017;101:68-74. doi:10.1016/j. ijmedinf.2017.02.005.

28. Zhang X, Han X, Dang Y, Meng F, Guo X, Lin J. User acceptance of mobile health services from users' perspectives: The role of self-efficacy and response-efficacy in technology acceptance. Inform Health Soc Care. 2017;42(2):194-206. doi:10.1080/17 538157.2016.1200053

29. Garavand A, Samadbeik M, Kafashi M, Abhari S. Acceptance of Health Information Technologies, Acceptance of Mobile Health: A Review Article. J Biomed Phys Eng. 2017;7(4):403408.

30. Zaires S, Perrakis G, Bekri E, Katrakazas P, Lambrou G, Koutsouris D. Chronic Disease Management via Mobile Apps: The Diabetes Case. In: Eskola H, Väisänen O, Viik J, Hyttinen J, eds. EMBEC \& NBC 2017. EMBEC 2017, NBC 2017. IFMBE Proceedings, vol 65. Singapore: Springer; 2017:177-180. doi:10.1007/978-981-10-5122-7_45. 